\title{
Frequency of Candida albicans serotypes in patients with denture-induced stomatitis and in normal
} denture wearers

\author{
MV MARTIN, DJ LAMB* \\ From the Department of Oral Pathology and *Restorative Dentistry, School of Clinical Dentistry, University \\ of Sheffield, Sheffield S10 2TA, England
}

SUMMARY A comparison has been made between the serotypes of oral Candida albicans taken from patients with denture-induced stomatitis and from a group of age and sex-matched controls. $C$ albicans isolates were obtained from the fitting surface of the denture, the palatal mucosa supporting the denture, and the buccal mucosa. Twenty-nine of the 30 patients sampled in the group affected by denture-induced stomatitis had only $C$ albicans serotype $A$ on their palatal mucosa and denture surface, while mixtures of serotypes were obtained from the buccal mucosa of these patients. Only one patient had serotype B isolates from the palatal mucosa and denture surface. In contrast, the control group had mixtures of A and B serotypes from both the denture surface and the palatal mucosa, as well as from the buccal sites sampled. It would appear from these results that denture-induced stomatitis is associated with the proliferation of a single $C$ albicans serotype, usually serotype A.

Denture-induced stomatitis (denture sore mouth) is a common disease estimated to affect over $60 \%$ of full denture wearers. ${ }^{1}$ The oral mucosa shows an erythematous reaction often extending to the limits of the upper denture-bearing area. The responsible organism, Candida albicans, can usually be isolated from both the fitting surface of the denture and the denture-bearing mucosa of affected patients. ${ }^{1-3}$

$C$ albicans is a common oral commensal of both dentate and denture-wearing patients and the reason for its occasional change to a pathogen is not clear. ${ }^{4}$ One hypothesis claims that infective strains are more virulent than others, ${ }^{56}$ but the recognition of virulent or avirulent strains is difficult because few methods have been devised for the differentiation of isolates of $C$ albicans.?

In 1963 Hasenclever and Mitchell ${ }^{8}$ identified two serotypes of $C$ albicans, $\mathrm{A}$ and $\mathrm{B}$, on the basis of the polysaccharide antigens on the cell wall. Subsequent epidemiological investigations of lesions on various bodily sites led to the conclusion that serotype A predominates. $^{89}$ Although the latter studies included oral samples, no investigation of the predominant serotypes from cases of denture-induced stomatitis has been traced in published reports.

Accepted for publication 23 December 1981
Three clinical types of denture-induced stomatitis may be described. Type 1 shows localised and often pinpoint hyperaemia; type 2 shows diffuse erythema; type 3 shows diffuse inflammation and papillary hyperplasia. ${ }^{10}$ It is not known whether either of the serotypes of $C$ albicans is specifically associated with any of the clinical types of dentureinduced stomatitis.

The aim of this investigation was to relate the prevalence of the two serotypes of $C$ albicans to the three clinical types of denture-induced stomatitis. It was further decided to investigate whether there were differences between the serotypes of $C$ albicans as found on the fitting surface of the denture, the denture-bearing mucosa and an area not covered by dentures, the buccal mucosa.

\section{Material and methods}

SUBJECTS

Patients with full dentures attending the Charles Clifford Dental Hospital were examined and those with denture-induced stomatitis selected. The disease was assessed as type 1,2 or 3 according to the criteria of Budtz-Jorgensen. ${ }^{10}$ With the exception of those suffering from any of the systemic conditions predisposing to candidosis, ${ }^{11}$ patients were included 
until three groups of ten (five men and five women) had been established, one of each clinical type. Healthy edentulous age- and sex-matched controls were also selected.

\section{MICROBIOLOGICAL METHODS}

The flora of all subjects was sampled using plain cotton wool swabs (Hospiswabs, Medical Wire Company, Kent). Patients suffering from dentureinduced stomatitis were swabbed at the affected mucosal site, the corresponding area of the fitting surface of the denture, and an unaffected site, the right buccal mucosa. Controls were swabbed in the same or equivalent areas.

The swabs were inoculated onto Sabouraud's agar (Lab M, London) and incubated at $37^{\circ} \mathrm{C}$ for $48 \mathrm{~h}$. From the resultant growth 10 colonies were removed and confirmed as $C$ albicans using the criteria of Lodder ${ }^{12}$ and the sugar assimilation and fermentation reactions of Martin and Schneidau ${ }^{13}$ and Dolan ${ }^{14}$ respectively. When Candida species other than $C$ albicans were identified, further isolates, if any, were selected from the plate and identified until $10 \mathrm{C}$ albicans colonies had been obtained.

\section{SEROLOGICAL METHODS}

Antisera to $C$ albicans serotype A strains NCPF 3153 and 3091 were raised in male New Zealand White rabbits $(3.0$ to $3.5 \mathrm{~kg})$ - two for each strain. Each animal was inoculated intravenously at intervals of $1,3,5,12$ and 15 days. The individual inoculum was prepared from $C$ albicans strains grown on Sabouraud's agar at $37^{\circ} \mathrm{C}$ for $24 \mathrm{~h}$. Before injection as a suspension in saline the inoculum was heat-killed at $65^{\circ} \mathrm{C}$ for $24 \mathrm{~h}$. The individual injections contained approximately $2 \times 10^{5}, 5 \times 10^{7}, 5 \times$ $10^{7}, 5 \times 10^{8}$ and $5 \times 10^{8}$ heat-killed cells respectively. The animals were bled 24 days after the first injection and thereafter every 28 days; a booster dose of approximately $5 \times 10^{8}$ heat-killed cells was given 14 days before each bleed. Sera from animals inoculated with the same strain were pooled. One further rabbit received saline injections only in order to produce a sham-immunised serum. The agglutination titre of the pooled sera was determined using the tube-agglutination method described by Hasenclever and Mitchell ${ }^{15}$ with the appropriate serotype A strain. To avoid non-specific reactions a twofold method was used, the initial dilution of the serum being $1 / 30$.

Specific serotype $A$ antisera were prepared by absorption of $C$ albicans strain 3156 against 3153 antisera, and strain $3118 \mathrm{C}$ cells against 3091 antisera. The cells for absorption were prepared and heat-killed in a similar manner to those for injection.
The cells for absorption were mixed with the appropriate antisera to approximately $33 \%$ packed-cell-volume. Following this they were incubated first at $45^{\circ} \mathrm{C}$ for $6 \mathrm{~h}$ and then at $4^{\circ} \mathrm{C}$ for $18 \mathrm{~h}$ prior to centrifuging at $5000 \mathrm{~g}$ for $10 \mathrm{~min}$. The resultant precipitate was discarded. The absorption procedure was repeated until the absorbed sera produced no agglutination with the serotype B C albicans cells, strains 3156 and $3118 \mathrm{C}$.

Antigenic extracts of the $C$ albicans strains isolated from the patients with and without dentureinduced stomatitis, together with those from the reference strains, were prepared by the formamide method of Fuller. ${ }^{16}$ The extracts were dissolved in phosphate-buffered saline at concentrations of 0.2 , 2.0 and $20 \mathrm{mg} / \mathrm{ml}$. Each concentration of antigenic extract was tested against undiluted absorbed, unabsorbed and sham-immunised antisera, using the double-diffusion technique (Ouchterlony) described by Evans. ${ }^{17}$ Precipitin lines at any of the concentrations were taken as a positive reaction. Serotype A strains were taken as those forming precipitin lines to antigenic extracts with either of the specific serotype A antisera. Antigenic extract failing to form precipitin lines with absorbed antisera but forming lines with either of the unabsorbed sera were taken as serotype B.

\section{CULTURES}

All cultures were maintained on Sabouraud's agar slopes at $4^{\circ} \mathrm{C}$ until required. C albicans strains 3091, $3118 C$, NCPF 3153 and NCPF 3156 were obtained form the Mycological Reference Laboratory, London School of Hygiene and Tropical Medicine, London. Strains NCPF 3153 and NCPF 3156 were subcultures of strains B311 and 792 described by Hasenclever. ${ }^{18}$

\section{Results}

The mean ages (yr) of the selected patients were as follows: type $1-52.2$ (men 51.2 , women 53.2 ); types 2-58.5 (men 53.4, women 63.6); type 3$53 \cdot 1$ (men 56.6, women 49.6).

\section{C albicans ISOLATIONS}

From every patient affected by denture-induced stomatitis, each site swabbed yielded at least 10 isolates of $C$ albicans. In contrast, from controls often fewer than 10 isolates could be obtained from each of the sites. Thus a total of 362 out of a desired 900 C albicans isolates were available from controls, 123 from palatal mucosa, 131 from the denture surface and 108 from the buccal mucosa. 


\section{ANTISERA}

The agglutination titres of pooled antisera against $C$ albicans NCPF 3153 and 3091 prior to absorption were found to be $1 / 1920$ and $1 / 960$ respectively. After absorption, titres of $1 / 480$ and $1 / 240$ were obtained to $C$ albicans strains 3153 and 3091 respectively. Precipitin lines were obtained at all concentrations of antigen with strains 3151 and 3091 using both of the specific serotype A antisera. Both unabsorbed sera gave precipitin lines against all concentrations tested of extracts of $C$ albicans strains $3153,3156,3091$ and $3118 \mathrm{C}$.

\section{DISTRIBUTION OF SEROTYPES}

The distribution of serotypes from patients with denture-induced stomatitis is shown in the Table. When sampling the denture surface and the palatal mucosa, no mixtures of isolates were discovered. Twenty-nine patients gave only serotype $A$ isolates from both sites, and a single patient only serotype $B$. In contrast, mixtures of $\mathrm{A}$ and $\mathrm{B}$ serotypes of $C$ albicans were always recovered when swabbing the buccal mucosa.

The distribution of serotypes from controls is also included in the Table. In every case mixtures of serotypes were isolated from the three sites swabbed. One isolate from the palatal mucosa of a patient in group 3 failed to give precipitin lines with any of the sera.

\section{Discussion}

Previous studies of $C$ albicans infections have reported a predominance of serotype $A{ }^{89}$ Similar results have been obtained in this study, serotype $A$ being recovered from all but one of the 30 affected patients. A single patient, suffering from type 3 denture-induced stomatitis as defined by BudtzJorgensen, ${ }^{10}$ had serotype B isolates recovered from the infected areas, showing serötype B infections to be very much less frequent.
While a single serotype of $C$ albicans was invariably found in the infected areas of patients suffering from denture-induced stomatitis, non-infected areas (the buccal mucosa) showed marked differences. In all non-infected areas sampled, mixtures of serotypes A and B were isolated. It would appear that infection is associated with proliferation of a single serotype to the exclusion of the other. The large number of isolates from affected patients (600) should ensure that sampling is representative and so confirm the conclusion.

The results illustrate how the presence of a denture can cause local changes in the environment of the mouth to the extent that a normally commensal organism can proliferate and exhibit pathogenicity. The local nature of the changes is emphasised by finding that even in affected patients mixtures of serotypes can be found when growth of $C$ albicans takes place outside the influence of the denture.

The presence of a denture is known to increase the carriage of Candida in healthy patients and it is reported that at least $55 \%$ of such patients have Candida present in their mounths. ${ }^{19}$ Our results contrast with this in that all denture wearers, healthy or not, were found to have Candida present in their mouths, although the number of isolates from the healthy group was small in comparison with the affected group (362 in comparison with 900). Despite the reduced numbers, mixtures of serotypes were invariably found.

The simple double-diffusion method of Hasenclever ${ }^{18}$ proved reproducible and reliable for serotyping the isolates. Most isolates gave precipitin lines with appropriate antisera at all three concentrations of the antigenic extract. Eleven gave precipitin lines only at $20 \mathrm{mg} / \mathrm{ml}$ antigen extract and not at lower concentrations. One isolate proved untypable. Repetition of the identification tests, together with tests described by Lodder, ${ }^{12}$ confirmed the isolate to be $C$ albicans, but it failed to give precipitin lines with any of the specific anti-A antisera or unabsorbed

Serotypes and distribution of $C$ albicans isolates from patients with denture stomatitis (controls in parentheses)

\begin{tabular}{|c|c|c|c|c|c|c|c|c|c|c|c|c|c|}
\hline \multirow{3}{*}{$\begin{array}{l}\text { Type of denture } \\
\text { stomatitis }\end{array}$} & & \multicolumn{12}{|c|}{ No and serotype of colonies isolated from } \\
\hline & & \multicolumn{4}{|c|}{ Infected palatal mucosa } & \multicolumn{4}{|c|}{ Denture surface } & \multicolumn{4}{|c|}{ Buccal mucosa } \\
\hline & & $A$ & & $\boldsymbol{B}$ & & $\boldsymbol{A}$ & & $B$ & & $A$ & & $B$ & \\
\hline Type 1 & $\begin{array}{r}\mathrm{M} \\
\mathrm{F}\end{array}$ & $\begin{array}{l}50 \\
50\end{array}$ & $\begin{array}{l}(8) \\
(7)\end{array}$ & $\begin{array}{l}0 \\
0\end{array}$ & $\begin{array}{l}(6) \\
(6)\end{array}$ & $\begin{array}{l}50 \\
50\end{array}$ & $\begin{array}{l}(11) \\
(13)\end{array}$ & $\begin{array}{l}0 \\
0\end{array}$ & $\begin{array}{l}(6) \\
(7)\end{array}$ & $\begin{array}{l}26 \\
28\end{array}$ & $\begin{array}{l}(17) \\
(11)\end{array}$ & $\begin{array}{l}24 \\
22\end{array}$ & $\begin{array}{l}(7) \\
(9)\end{array}$ \\
\hline Type 2 & $\begin{array}{c}\mathbf{M} \\
\mathbf{F}\end{array}$ & $\begin{array}{l}50 \\
50\end{array}$ & $\begin{array}{l}(12) \\
(10)\end{array}$ & $\begin{array}{l}0 \\
0\end{array}$ & $\begin{array}{l}(8) \\
(13)\end{array}$ & $\begin{array}{l}50 \\
50\end{array}$ & $\begin{array}{l}(18) \\
(14)\end{array}$ & $\begin{array}{l}0 \\
0\end{array}$ & $\begin{array}{r}(11) \\
(7)\end{array}$ & $\begin{array}{l}25 \\
20\end{array}$ & $\begin{array}{r}(10) \\
(6)\end{array}$ & $\begin{array}{l}25 \\
30\end{array}$ & $\begin{array}{l}(11) \\
(12)\end{array}$ \\
\hline Type 3 & $\stackrel{\mathbf{M}}{\mathbf{F}}$ & $\begin{array}{l}50 \\
40\end{array}$ & $\begin{array}{l}(14) \\
(16)^{*}\end{array}$ & $\begin{array}{r}0 \\
10\end{array}$ & $\begin{array}{r}(14) \\
(8)\end{array}$ & $\begin{array}{l}50 \\
40\end{array}$ & $\begin{array}{l}(17) \\
(13)\end{array}$ & $\begin{array}{r}0 \\
10\end{array}$ & $\begin{array}{l}(8) \\
(3)\end{array}$ & $\begin{array}{l}24 \\
19\end{array}$ & $\begin{array}{l}(5) \\
(5)\end{array}$ & $\begin{array}{l}26 \\
31\end{array}$ & $\begin{array}{l}(8) \\
(7)\end{array}$ \\
\hline
\end{tabular}

${ }^{*}$ One isolate was not typable as either $\mathrm{A}$ or $\mathrm{B}$. 
sera. Antisera to $C$ tropicalis and $C$ stellatoidea have been reported to react with $C$ albicans ${ }^{1820}$ but this isolate failed to give precipitin lines with either of these antisera (results not shown). Thus the isolate may be an antigenically atypical form of $C$ albicans or alternatively may be an example of the serotype $\mathrm{C}$ of $C$ albicans suggested by Müller and Kirchoff. ${ }^{21}$ No specific anti- $C$ albicans serotype $C$ antisera were available to resolve this.

Recently it has been shown ${ }^{5}$ that $C$ albicans strains taken from patients with denture-induced stomatitis and injected into the skin of rats produce more extensive cutaneous lesions than strains taken from healthy carriers or skin candidoses; it is thus possible that strains from pathological sites may be different from those in unaffected areas. Although in our work no mixtures of serotypes A and B were found in the affected areas, it is important to emphasise that multiple strains of $C$ albicans may be present because it is not yet known whether different strains of $C$ albicans have the same polysaccharide antigen and hence the same serotype.

The authors acknowledge the help of Miss M Norris in the selection of patients for this study. Ms D Teale, Mr N Cameron and Mr D Thompson are thanked for their technical assistance. The helpful comments of Professor CJ Smith in the preparation of this manuscript are also acknowledged. Professor EL Hampson, University of Sheffield, is also thanked for access to the patients used in this study.

\section{References}

${ }^{1}$ Budtz-Jorgensen E, Stenderup A, Grabowski M. An epidemiologic study of yeasts in elderly denture wearers. Community Dent Oral Epidemiol 1975;3:115-9.

${ }^{2}$ Cawson RA. Denture sore mouth. II The role of Candida. Dental Practice and Dental Record 1965;16:138-42.

${ }^{3}$ Davenport JC. The oral distribution of Candida in denture stomatitis. Br Dent J 1970;129:151-6.

4 Arendorf TM, Walker DM. The prevalence and intra-oral distribution of Candida albicans in man. Arch Oral Biol 1980;25: 1-10.
${ }^{5}$ Abdelghaffer AA, Russell C. The role of strain difference and tetracycline on the production of subcutaneous lesions by Candida albicans in experimental rats. Sabouraudia 1979;17:210-7.

- Richardson MD, Smith H. The interaction of attenuated and virulent strains of Candida albicans with human and mouse phagocytes. Soc Gen Microbiol $Q$ 1980;7:131.

' Warnock DW, Speller DC, Day JM, Farrell AJ. Resistogram method for the differentiation of strains of Candida albicans. $J$ Appl Bacteriol 1979;46:571-8.

${ }^{8}$ Hasenclever HF, Mitchell WO. Antigenic studies of Candida IV. The relationships of antigenic groups of Candida albicans to their isolation from various clinical specimens. Sabouraudia 1963;2:201-4.

'Stallybrass FC. The incidence of serological groups of Candida albicans in Southern England. J Hyg 1964;62:395-9.

${ }^{10}$ Budtz-Jorgensen E. Clinical aspects of Candida infection in denture wearers. J Am Dent Assoc 1978;96:474-9.

"Odds FC. Candida and Candidoses Leicester: Leicester University Press, 1979.

${ }^{12}$ Lodder J. The yeasts: a taxonomic study. Amsterdam: North Holland Publishing Co, 1970.

${ }^{13}$ Martin MV, Schneidau JD. A simple and reliable test for the identification of Candida species. Am J Clin Pathol 1970;53:875-9.

${ }_{14}$ Dolan CT. A practical approach to the identification of yeast-like organisms. Am J Clin Pathol 1971;55:590-1.

is Hasenclever HF, Mitchell WO. Antigenic relationships of Torulopsis glabrata and seven species of the genus Candida. $J$ Bacteriol 1960;79:667-81.

${ }^{16}$ Fuller AT. The formamide method for the extraction of polysaccharides from haemolytic streptococci. $\mathrm{Br} J$ Exp Pathol 1938;19:130-9.

${ }^{17}$ Evans EGV, ed. Serology of fungal infection and farmers' lung disease. Leeds: British Society of Mycopathology, 1976.

${ }^{18}$ Hasenclever HF. The antigens of Candida albicans. Am Rev Respir Dis 1965;93suppl:150-8.

${ }^{19}$ Arendorf TM, Walker DM. Oral Candidal populations in health and disease. Br Dent J 1979;147:267-72.

${ }^{20}$ Hasenclever HF, Mitchell WO. Antigenic studies of Candida. III Comparative pathogenicity of Candida albicans group A, group B and Candida stellatoidea. J Bacteriol 1961;82:574-7.

${ }^{21}$ Müller H-L, Kirchoff G. Serologische Typen von Candida albicans. Zentrabl Bakteriol [Orig A] 1969;210:114-21.

Requests for reprints to: Dr MV Martin, Department of Oral Pathology, University of Sheffield, 31 Claremont Crescent, Sheffield S10 2TA, England. 